\title{
Effect of Oral Administration of Artesunate on the Histology of the Kidney in Albino Rat.
}

\author{
Danladi Sambo Amaza ${ }^{1}$, Mumuni Momoh ${ }^{1}$, Joseph Vandi Zirahei ${ }^{1}$, Aminu \\ Ahmed Rufai ${ }^{1}$, Nuhu Sambo ${ }^{2}$, Lucy Amos ${ }^{3}$ and M. Tarfa ${ }^{1}$ \\ ${ }^{1}$ Department of Human Anatomy, College of Medical Sciences, University of Maiduguri, Borno State, Nigeria \\ ${ }^{2}$ Department of Human Physiology, College of Medical Sciences, University of Maiduguri, Borno State, \\ Nigeria. \\ ${ }^{3}$ Department of Human Anatomy, Faculty of Basic Medical Sciences, Ahmadu Bello University Zaria, Nigeria.
}

\begin{abstract}
The effect of oral administration of Artesunate on the histology of the Kidney of Albino Rat was determined histologically. Thirty Albino rats weighing $80-175 \mathrm{~g}$ were divided into five groups (A-E) of five rats each. Group A (control) was give equal volume of distilled water daily. Group B received $4 \mathrm{mg} / \mathrm{kg} / \mathrm{day}$ of Artesunate for 5 days and were sacrificed on the 6th day. Group C were given $4 \mathrm{mg} / \mathrm{kg}$ of Artesunate for the $1^{\text {st }}$ day, then $3 \mathrm{mg} / \mathrm{kg} /$ day of Artesunate for 8 days and sacrificed on the $10^{\text {th }}$ day. Group D received $4 \mathrm{mg} / \mathrm{kg} / \mathrm{day}$ of Artesunate for the $1^{\text {st }}$ day, then $3 \mathrm{mg} / \mathrm{kg} / \mathrm{day}$ of Artesunate for 12 days and sacrificed on the $14^{\text {th }}$ day. Group $\mathrm{E}$ served as recovery group which received equal treatment as group D above and were left for 10 days later on vital feed and water and were sacrificed on the $23^{\text {rd }}$ day. The route of administration was orally by the use of the orogastric tube. The kidneys were removed and transferred immediately into $10 \%$ formalin. There were no marked differences between the change in weight of the control and the experimental. Administration of Artesunate to rats produced moderate to severe glomerular degeneration, focal haemorrhage, oedema, congested blood vessels, cloudy swelling of the tubules, necrosis of the tubule both in cortex and medulla. These findings were observed to be dose dependent. Artesunate may have acted as toxin to the neurons, affecting their structural integrity. It is therefore recommended that further studies aimed at corroborating this findings be carried out
\end{abstract}

Keywords: Artesunate, Kidney histology, Toxicity, Antimalaria

\section{INTRODUCTION}

Malaria remains one of the world's most significant health problems despite increasing research and control efforts [1]. More than two billion people are at risk of malarial infection, over a quarter of a billion cases are thought to occur annually and at least a million people die every year as a result of the disease alone or in combination with other condition [2]. At present Malaria is a leading cause of mortality and morbidity in developing countries of the world of which Nigeria is not an exception, and it remains a major public health problem in endemic regions [3]. Resistance to available malarial drugs is increasing and creating a need for new drugs that are well tolerated in human systems. As a result of this difficult situation, artemisinin and its derivatives (artesunate, artemether, arteether, and dihydroartemisinin) have given renewed hope for combating resistant malaria $[4,5]$. These drugs have gained considerable prominence in the chemotherapy of both uncomplicated and severe falciparum malaria by demonstrating high activity against multidrug-resistant falciparum strains with low toxicity profiles [6].

Artesunate is a drug used to treat malaria, especially chloroquine resistant malaria in Nigeria and in other developing countries. It is a semi- synthetic derivative of artemisinin, the active compound of the Chinese herb Artemisia annua which consists of the sodium succinyl salt of dehydroartemisinin [7]. It has been used against multidrug- resistant strains of plasmodium falciparum [8, 9 and 10]. Artesunate is well tolerability by human systems and it lacks significant adverse side effects after use [11]. Artemisinin is toxic to malaria parasites because of the presence in it high amount of iron in the form of heme molecules. It generates high levels of Reactive Oxygen Species (free radicals) which after metabolism cause macromolecular damages and cell death [12].

The use of these drugs should be controlled and restricted to proven multi-drug resistance on severe malaria in order to preserve their efficacy [13] and avoid emergence of resistant strains. In malaria endemic areas such as Nigeria, self medication is quite common and purchase of antimalarials in the open market is rampant [14]. The possibility of administering overdose and misappropriation in the usage of antimalarials are very common. Drugs though useful in the treatment of disease conditions could also produce toxic effects in the individual. This toxic effect may be harmful to the patient [15]. 
The mechanism of action of these drugs and their ability to accumulate in the red blood cell being its primary site of action, had raised questions regarding the safety of artemisinin and its derivatives, especially artesunate which is fast gaining wide-spread acceptance in most malaria endemic regions of the world.

Moreover, since artemisinine compounds (artesunate) cross the blood brain barrier, they have been tested as a treatment of toxoplasmosis [15]. Artesunate and its active metabolite dihydroartemisin are potent blood schizonticides; highly effective against multi-drug resistant strains of plasmodium falciparum hence its increasingly wide usage for the treatment and management of malaria [16]. It is used in combination therapy and is effective in cases of uncomplicated P. falciparum. Several studies on artesunate showed evidence of toxicity on the brain stem [17, 18], superior colliculus [19], stomach [20], testis [21] and liver [22]. The present study evaluated the toxicological influence of different artesunate dosage administration in Albino rats, as administered to human. The objective of the study therefore was to examine the effects of artesunate on the histology of the kidney in Albino rats, in view of the fact that the effect of artesunate on the morphology of the liver has already been determined by [22].

\subsection{Preparation of Artesunate Solution}

\section{MATERIAL AND METHOD}

The Artesunate tablets used for this experiment were manufactured by Mekophar Chemical Pharmaceutical Join-Stock Company, Ho Chi Minh City, Vietnam and purchased from Pharmacy Department, University of Maiduguri Teaching Hospital, Borno State, Nigeria. The drug solution was made with distilled water; $50 \mathrm{mg}$ of Artesunate was dissolved in $10 \mathrm{mls}$ of distilled water. After sedimentation the upper liquid portion was drained using a needle and syringe and given to the rats in the experimental group according to their body weight with the aid of orogastric tube for a period of seven days. The dosage of Artesunate administered was according to WHO recommendation of $4 \mathrm{mg} / \mathrm{kg}$ body weight daily for 3 days followed by $2 \mathrm{mg} / \mathrm{kg}$ body weight daily for the remaining 4 days. All the animals were weighed before and at the end of experiment.

\subsection{Experimental Animals}

Thirty (30) male albino rats weighing 80-175g and aged between 6-9weeks were used for the study. The rats were obtained from the animal house of the Department of Anatomy, University of Jos and allowed to acclimatize in the animal house of the Department of Human Anatomy, College of Medical Sciences, University of Maiduguri, for 2 weeks prior to experimentation. They were kept in properly ventilated cages, where bedding was replaced every two days, at a room temperature of about $27 \mathrm{oC}$ and 12 hour light/dark cycle. The rats were fed with growers' marsh and water from tap ad libitum.

\subsection{Experimental Design}

The rats were divided into five groups (A-E) of five rats each and labeled accordingly with a dilute solution of picric acid for easy identification. Group A served as control and was give equal volume of distilled water through Orogastric tube daily throughout the course of the experiment and had free access to feed. Group B receives $4 \mathrm{mg} / \mathrm{kg} /$ day of Artesunate for 5 days and sacrificed on the 6th day. Group C was given $4 \mathrm{mg} / \mathrm{kg}$ of Artesunate for the 1 st day, then $3 \mathrm{mg} / \mathrm{kg} / \mathrm{day}$ of Artesunate for 8 days and sacrificed on the 10th day. Group D receives $4 \mathrm{mg} / \mathrm{kg} /$ day of Artesunate for the 1 st day and then $3 \mathrm{mg} / \mathrm{kg} /$ day of Artesunate for 12 days and sacrificed on the 14th day. The fifth group (Group E) served as recovery group, received equal treatment with group D above and then were left for 10 days later feeding on vital feed (grower's mash) and water and were sacrificed on the 23rd day. The route of administration was orally by the use of the orogastric tube sterilized with K-Y gel before use. Before the kidneys were removed, the fixing solution (10\% formalin) was ready in the specimen bottles which were labeled according to their respective group. Each rat was anaesthetized with cotton wool soaked in chloroform, and then supported on dissecting bed in dorsal decubitus position; the limbs were abducted and held with pins to keep the muscles in position. Scalpel blade, sharp scissors were then used to cut and open up the abdominal region, using forceps the kidneys were held and removed and transferred immediately into already prepared $10 \%$ formalin in specimen bottles.

\subsection{Histological Analysis}

All kidneys obtained were procured using the routine histological laboratory technique. The fixed kidney tissues were sectioned (5-micron thickness) and sections firstly stained with basic dyes, of Heamatoxylin and Eosin (H\&E) according to Conn (Conn, 1946) procedure. A comparative microscopic examination was done using microscope to see if Vernonia amygdalina was effective to restore the normal histo-architecture of the damaged kidney due to phenylhydrazine administration. 


\subsection{Statistical Analysis}

Numeric data obtained from the study were expressed as the mean value \pm standard error of mean (SEM). Differences among means of control and treated group were determined using statistical package (Instant Biostatistics, Version 3, Graphpad Software Inc. 2002). A probability level of less than 5\% (P<0.05) was considered significant.

\subsection{GROSS ANATOMICAL OBSERVATION \\ III. Results}

It was observed that the faecal matter of experimental groups of the animal became slightly watery two (2) days after commencement of administration of Artesunate. However, these faecal matters returned to normalcy after the fourth day. There were also no marked differences between the change in weight of the control and the experimental groups as changes in these groups were found not quite significant with $\mathrm{p}$-value of 0.0986 .

Table 1: EFFECT OF ARTESUNATE ON THE BODY WEIGHT OF THE RATS.

\begin{tabular}{lllll}
\hline Group & Initial body weight $(g)$ & Final body weight $(g)$ & Difference Body weight $(g)$ & P-Value \\
\hline A & $115-18 \pm 12.40$ & $128 . \mathrm{g} \pm 21.8$ & $13.72 \pm 9.40$ & $0.60(\mathrm{~ns})$ \\
B & $125.1 \pm 11.90$ & $128.60+10.0$ & $3.50 \pm 1.90$ & $0.83(\mathrm{~ns})$ \\
C & $118.3 \pm 14.3$ & $123.0 \pm 14.40$ & $4.70 \pm 0.10$ & $0.82(\mathrm{~ns})$ \\
D & $138.8 \pm 10.80$ & $143.8 \pm 10.7$ & $5.00 \pm 0.10$ & $0.82(\mathrm{~ns})$ \\
E & $118.8 \pm 13.2$ & $142.9 \pm 12.3$ & $24.10 \pm 0.90$ & $0.23(\mathrm{~ns})$ \\
\hline
\end{tabular}

Mean \pm SEM $\quad$ SEM=Standard Error of Mean, $\mathrm{g}=$ grammes, $\mathrm{ns}=$ not significant

\subsection{Histological Observations}

In general, it was observed that administration of Artesunate to rats produced moderate to severe glomerular degeneration, focal haemorrhage, oedema, congested blood vessels, cloudy swelling of the tubules, necrosis of the tubule both in cortex and medulla. These pathological effects were observed to be dose and duration of the dose dependent. In other words, the higher the dose given, the more severe the damage observed and the longer the duration of the dose the more severe the damage observed. In group E which was left for 10 days post treatment before sacrificed showed no sign of recovery as severity of glomerular degeneration and tubular necrosis in the cortex persisted.

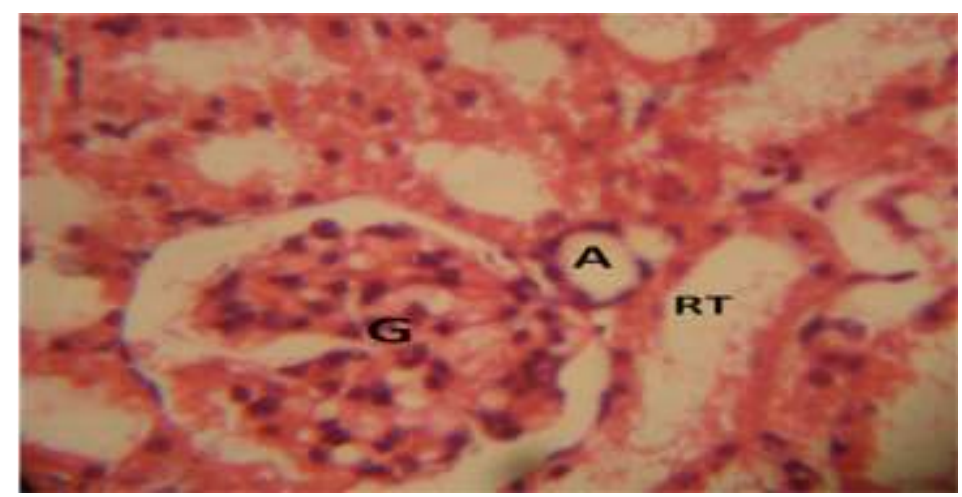

Fig.1 Photomicrograph showing normal Glomerulus (G) and Renal Tubules (RT) in the cortex. Group A (Control): H\&E x 400.

Group B that received $4 \mathrm{mg} / \mathrm{kg} / \mathrm{day}$ of Artesunate for 5 days showed moderate glomerular degeneration, oedema, focal haemorrhage, congested blood vessels, and cloudy swelling of the tubules as shown in fig 2. 


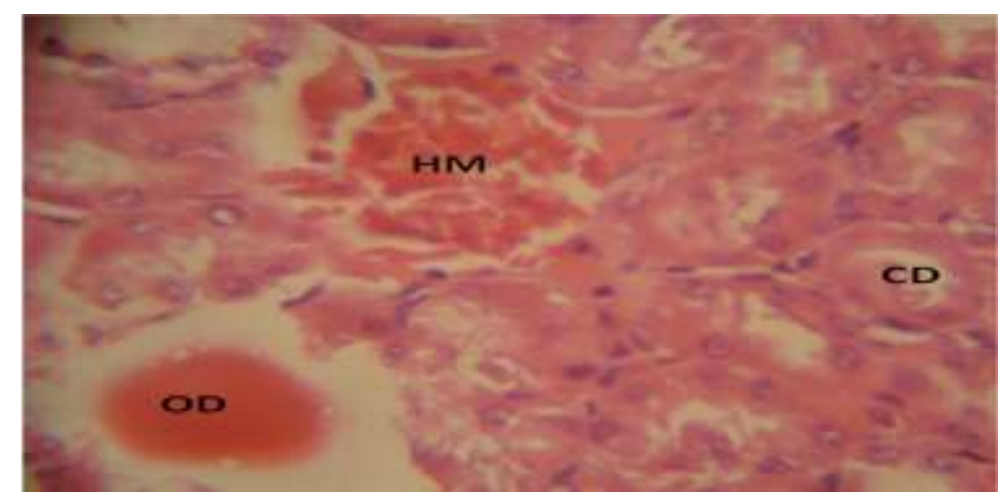

Fig. 2 Photomicrograph showing moderate oedema (OD), focal haemorrhage (HM), cloudy swelling of the tubules (CD). GROUP B $(4 \mathrm{mg} / \mathrm{kg}, 3 \mathrm{mg} / \mathrm{kg}$ of Artesunate): $\mathrm{x} 400$

Group C that received $4 \mathrm{mg} / \mathrm{kg}$ of Artesunate for the $1^{\text {st }}$ day, then $3 \mathrm{mg} / \mathrm{kg} /$ day of Artesunate for 8 days revealed severe multi-focal glomerular degeneratoion, haemorrhage, necrosis of the tubules as shown in fig 3 .

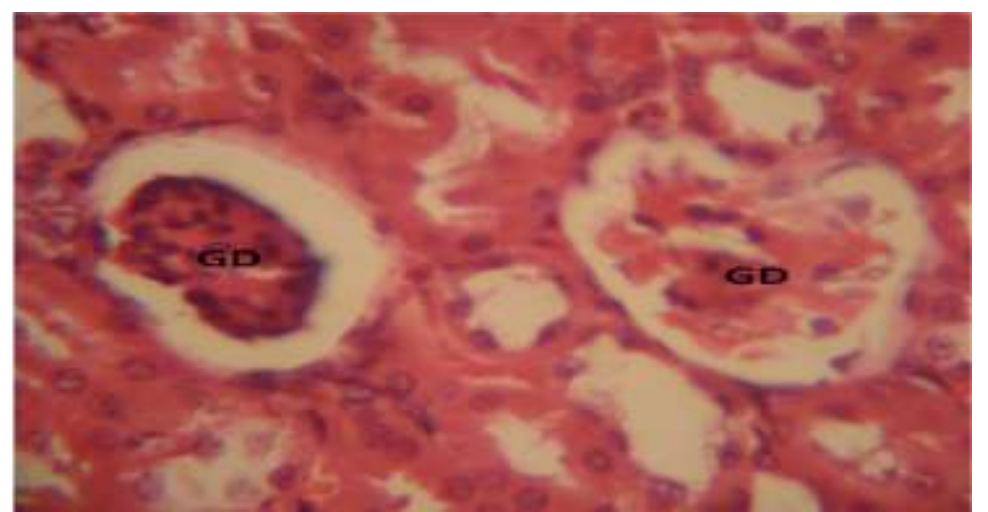

Fig. 3 Photomicrograph showing Severe glomerular degeneration (GD) Group C (4mg/kg, 3mg/kg of Artesunate): $\mathrm{x} 400 \mathrm{H} \& \mathrm{E}$

Group D that received $4 \mathrm{mg} / \mathrm{kg}$ of Artesunate for the $1^{\text {st }}$ day, then $3 \mathrm{mg} / \mathrm{kg} /$ day of Artesunate for 12 days showed severe focal congestion in the cortex, interitial haemorrhage and pale staining of the tubules in the medulla as shown in fig 4.

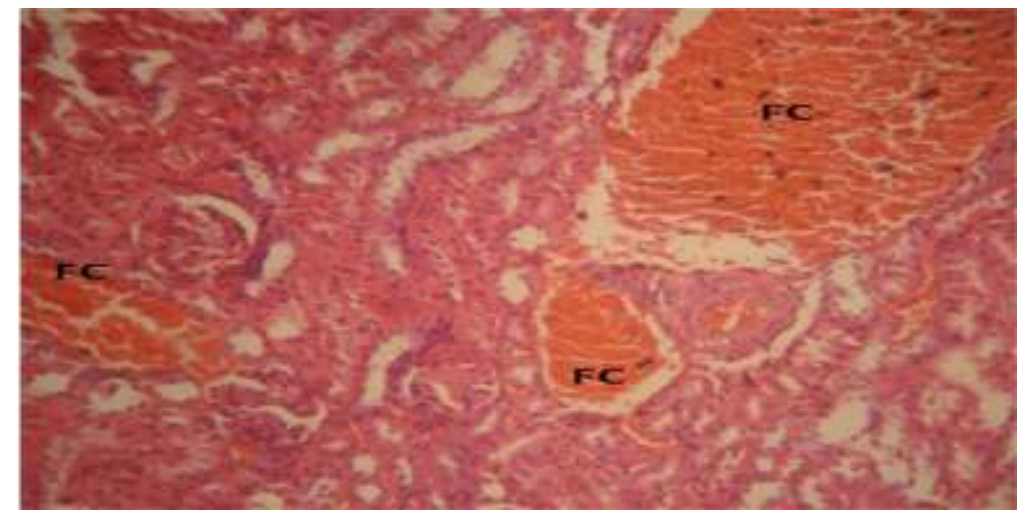

Fig.4 Photomicrograph showing severe focal congestion in the cortex (FC). Group D (4mg/kg, 3mg/kg of Artesunate): X400 H\&E

Group E that received $4 \mathrm{mg} / \mathrm{kg}$ of artesunate for the $1^{\text {st }}$ day, then $3 \mathrm{mg} / \mathrm{kg} /$ day of artesunate for 12 days thereafter, left 10 days post treatment before sacrificed showed severe glomerular degeneration, tubular necrosis in the cortex and medulla as shown in fig 5 . 


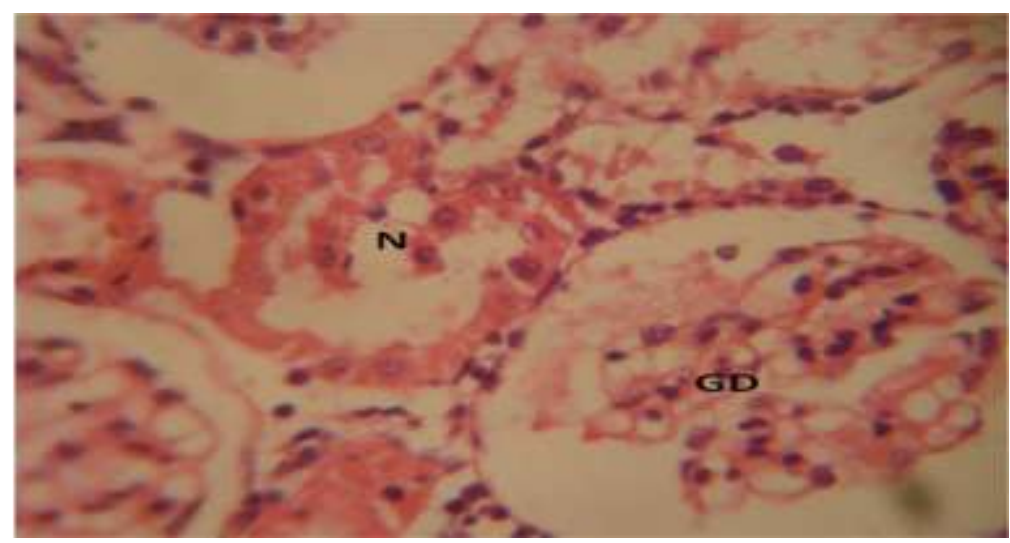

Fig. 5 Photomicrograph showing severe glomerular degeneration (GD) and necrosis of the tubule (N). Group E $(4 \mathrm{mg} / \mathrm{kg}, 3 \mathrm{mg} / \mathrm{kg}$ of Artesunate +10 days PT): X400 H\&E

\section{Discussion}

Based on their body weight differences, the Artesunate had no significant effect on the body weight of all the rats. Administration of Artesunate to rats at various doses showed that, there was no significant $(\mathrm{P}>0.05)$ differences between the weight of experimental groups with that of the control group (table 1).

Histological examination of the tissue section from rats administered with Artesunate in the present study revealed moderate to severe glomerular degeneration, focal haemorrhage, oedema, congested blood vessels, cloudy swelling of the tubules, degenerative changes of the tubules, severe focal congestion in the cortex, pale staining of tubules. These pathological features are however observed to be dose dependent as well as the duration for which these doses were administered. There were no signs of recovery in the group E left for 10 days post treatment before they were sacrificed, as there was persistence in severity of degeneration of glomeruli and tubules in the cortex These lesions observed is consistent with the earlier findings of [23] in which artesunate was observed to have caused some degenerative and necrotic changes, cellular hypertrophy and increased intercellular vacoulation in the stroma of stomach of rats treated with Artesunate. This study is also consistent with the findings of [24] who observed that artesunate at normal dose was toxic to the liver cells, and in another study by [22] where it was documented that artesunate at normal dose has a toxic effect on the liver cells and could be a potential hepatotoxic drug. According to [22], artesunate may have acted indirectly through generation of high levels of Reactive Oxygen Species which Artesunate usually generate through its anti-malarial activities or may act directly as toxin to the cells of the liver, affecting their cellular integrity and causing defect in membrane permeability and cell volume homeostasis. In cellular necrosis, the rate of progression depends on the severity of the environmental insults. According to [25] the greater the severity of the insults the more rapid the progression of neuronal injury. This is a true process for toxicological insult to the brain and other organs [26]. Hence it can be deduced from this present findings that even normal dose of Artesunate resulted in toxic effects on the kidney of albino rats. However the present finding is contrary to that of [27], who documented that amodiaquine-artesunate combination is not neurotoxic in rats. In this study Artesunate may have acted as toxin to the neurons, affecting their structural integrity and causing defects in membrane permeability and cell volume homeostasis as suggested by early researchers.

\section{Conclusion}

This study has demonstrated that prolonged administration of Artesunate to Albino rats could be toxic to the nephrons of the kidney even at normal doses; it was also observed that there were no sign of recovery after 10 days withdrawal of administration of the drug to the rats. However there were no significant changes in the weights of the rats studied. It is therefore, recommended that this study be carried out in humans with extended period of more than 10 days post treatment in recovery groups. People who take Artesunate as prophylaxis or as curative agent against multi-drugs resistant malaria should do so with care.

\section{References}

[1] Curtis C. F,Workshop on Bednet at the International Congress of Tropical Medicine JPM Saint ZOOL. 2, $1993,63-68$.

[2] WHO. Reproductive Risk Assessment of Antimalaria Therapy with Artemisinin Compounds" - Reports of an Informal Consultation Convened by WHO Geneva, 2002 May 29-30.

[3] Breman, J.G., M .S. Alilio and A. Mills, Conquering the intolerable burden of malaria: what's new, w hat's needed: a summary. Am. J. Trop. Med. Hyg., 71, 2004, 1-15.

[4] Hein, T.T., . An overview of the clinical use of artemisinin and its derivatives in the treatment of falciparum malaria in Vietnam. Tran. R. Roc. Trop. Med. Hyg., 88(Suppl), 1994, 7-8.

[5] Harinasuta, T. and J. Karbwang. Qinghaosu: A Promising Antimalarial. JAMA SEA; 3.1994 
[6] Chanthap, L., R. Tsuyuoka, K. Na-Bangchang, N. Nivanna, D. Suksom, T. Sovannarith and D. Socheat, Investigation of bioavailability, pharmacokinetics and safety of new pediatric formulations of artesunate and mefloquine Southeast Asian. J. Trop. Med. Public Health, 36(1), 2005 34-43.

[7] Ittarat W, Udomsangpeth R, Chotivanich RKT, Looareesuwan S, The effects of quinine and artesunate treatment on plasma tumor necrosis factor levels in malaria infected patients. Southeast Asian Journal of Tropical Medicine and Public Health, 30, 1999 7-10.

[8] Hien, T.T. and White N.Y. Qinghaosu, Lancet 341,1993, 603-608.

[9] Batty KT, Ilett KF, Davis T, Chemical stability of artesunate injection and proposal for its administration by intravenous infusion. Journal of Pharmacy and Pharmacology, 48, 1996, 22-26.

[10] Price R, van Vugt M, Nosten F, Luxemburger C, Brockman A, Phaipun L, Chonsuphajaissiddi T, White N, Artesunate versus artemether for the treatment of recrudescent multidrug-resistant falciparum malaria. American Journal of Tropical Medicine and Hygiene, 59, 1998, 883-888.

[11] Looareesuwan S. Overview of clinical studies on artemisinin derivatives in Thailand. Transactions of the Royal Society of Tropical Medicine and Hygiene, 88 (supplement), 1994, s9-s11.

[12] Anderson, K.M., Seed T., Ou, D. and Harris, J.E. Free Radicals and Reactive oxygen Species in programmed Cell Death. Med Hypothesis, 52, 2002, 457-63

[13] Mulenga M. Facing drug resistance: therapeutic option for treatment of uncomplicated Plasmodium falciparum malaria in adult Zambians. Journal of Medicine and Health Sciences, 2(1), 1998, 11-20.

[14] Nwanjo H, Oze G, Acute Hepatotocixity Following Administration Of Artesunate In Guinea Pigs . The Internet Journal of Toxicology, 4 (1). 2007

[15] Udonan EI. Pharmacology made simple for Nurses and Allied professionals. Jireh Printing Press, Ikot Ekpene. 2000, 31-36.

[16] Van Agtmael, M.A., S. Cheng-Qi, J.X. Qing, R. Mull and C.J. Van Boxtel, Multiple dose pharmacokinetics of artemether in Chinese patients with uncomplicated falciparum malaria. Int. J. Antimicrob. Agents, 12, 1999, 151-158.

[17] Genovese, R.F., B.D. Newman and T.G. Brewer, Behavioral and neural toxicity of the artemisinin antimalaria arteether, but not artesunate and artelinate in rats. Pharmacol. Biochem. Behav., 67(1),2000, 37-44.

[18] Nontprasert, A., S. Pukrittayakamee, A.M. Dondorp, R. Clemens, S. Looareesuwan and N.J. White, Neuropathologic toxicity of artemisinin derivatives in a mouse model. Am. J. Trop. Med. Hyg., 67, 2002, 423-429.

[19] Eweka, A.O. and J.O. Adjene, Histological studies of the effects of oral administration of Artesunate on the superior colliculus of adult wistar rats. Internet J. Trop. Med., 4(2), 2008a, 1-9.

[20] Eweka, A.O. and J.O. Adjene, Histological studies of the effects of oral administration of artesunate on the stomach of adult wistar rats. Internet J. Health, 7(1)2008b, 1-7.

[21] Izunya AM, Nwaopara AO, Aigbiremolen A, Oaikhena GA, Body and Testicular Weight Changes in Adult Wistar Rats Following Oral Administration of Artesunate. Research Journal of Applied Science, Engineering and Technology, 2(3), 2010a, $302-306$.

[22] Izunya, A.M., Nwaopara, A.O. Aigbiremolen, A, and Odike, M.A.C, Histological Effects of Oral Administration of Artesunate on the Liver in Wistar Rats. Res. J. Appl. Sci. Eng. Technol., 2(4), 2010b, 314-318.

[23] Andrew, O. Ewaka, and Adjene, J.O. Histological studies of the effect of Oral Administration of Artesunate On The Stomach Of Adult Wistar Rats. The Internet Journal of Health. 7 (1), 2008.

[24] Hassan M.I, Histological Effect of Oral Administration of Artesunate on The Liver of Wistar Rat Research Journal of Applied Science, Engineering and Technology 2, 2006, 314.

[25] Ito, U., M. Sparts, J.R. Walker and I. Warzo. Experimental cerebral ischemia in magolian gerbils (1), light microscope observations. Acta Neuropathol., USA, 32, 2003, 209-223.

[26] Martins, L.J., N.A. Al-Abdulla, J.R. Kirsh, F.E. Sieber and C. Portera-Cailliau, 1978. Neurodegeneration in excitotoxicity, global cerebral ischaemia and target Deprivation: A perspective on the contributions of apoptosis and necrosis. Brain Res. Bull., 46(4), 1978, 281-309.

[27] Ekeoma, A.O., Ekong, M.B. Igiri, A.O, and Ekanem, T.B. Effect of Amodiaquine-artesunate combination on some Macromolecules in the Brain of Albino Rats. Internet Journal of Health ISSN: 1528-8215, (8)1. 2008 